\title{
ELECTRICAL ENERGY REQUIREMENTS FOR ATW AND FUSION NEUTRONS
}

\author{
by \\ D.L. JASSBY and J.A. SCHMIDT \\ Princeton Plasma Physics Laboratory \\ Princeton, New Jersey
}

\begin{abstract}
This note compares the electrical energy requirements of accelerator (ATW) and fusion plants designed to transmute nuclides of fission wastes. Both systems use the same blanket concept but for each source neutron the fusion system must utilize one blanket neutron for tritium breeding. The ATW and fusion plants are found to have the same electrical energy requirement per available blanket neutron when the blanket coverage is comparable and fusion $\mathrm{Q} \approx 1$, but the fusion plant has only a fraction of the energy requirement when $Q>1$. If the blanket thermal energy is converted to electricity, the fusion plant and ATW have comparable net electrical energy outputs per available neutron when $Q \geq 2$.
\end{abstract}




\section{INTRODUCTION}

The term ATW denotes "Accelerator Transmutation of Waste" $(\underline{1}, \underline{2})$. Fusion devices have also been considered as potential neutron sources for transmutation (3). Comparisons between fusion and accelerator transmutation plants must be made on the basis of neutrons available for the transmutation function. In our terminology "source neutrons" are fusion or spallation neutrons, while "available neutrons" are neutrons in the blanket potentially available for fissioning or otherwise transmuting waste nuclides. In the case of a fusion plant fueled with D-T, for each source neutron one neutron in the blanket must be used to breed tritium.

The principal purpose of this note is to compare the electrical energy requirements per available neutron of ATW and fusion plants. We also roughly estimate the relative capital costs per available neutron.

We use the following definitions:

$\eta_{\mathrm{b}}=$ electrical efficiency of the ATW beam $=0.45$

$\eta_{\mathrm{p}}=$ electrical efficiency of fusion plasma heating $=0.40$

$\eta_{\mathrm{e}}=$ conversion efficiency of blanket thermal energy to electricity

$\mathrm{k}=$ chain reaction neutron multiplication constant in the ATW blanket, where $\mathrm{k}$ is the ratio of neutrons in successive generations $(\mathrm{k}<1)$

$\mathrm{k}^{\prime}=$ neutron multiplication constant in the fusion device blanket

\section{Basis of the Analysis}

1) The ATW and fusion device use the same blanket concept, but the fusion blanket is modified for tritium breeding. (While coverage of the neutron source by the 
waste modules may be less than $100 \%$, the fusion device needs full blanket coverage for tritium breeding alone.)

2) The fusion device produces one source neutron per (17.6/ Q) $\mathrm{MeV}$ of plasma heating energy, where $\mathrm{Q}$ is the ratio of fusion power to plasma heating power.

3) The fusion device has superconducting coils, but the plant requires $50 \mathrm{MWe}$ for non-plasma components, such as cryogenic refrigeration, auxiliary resistive coils, vacuum pumping and blanket coolant systems.

4) The ATW produces 40 spallation neutrons per ion at beam energy of $1.0 \mathrm{GeV}$ (i.e., an expenditure of $25 \mathrm{MeV}$ per source neutron).

5) The ATW plant requires negligible electrical power other than for ion beams.

6) Neutron generation in the blanket occurs only by fission, $(n, 2 n)$ reactions being relatively insignificant. Each fission reaction gives 3.0 neutrons (typical for Pu239) and produces $180 \mathrm{MeV}$.

\section{NEUTRON AND ENERGY PRODUCTION IN THE BLANKET}

The total neutron multiplication in the ATW blanket is $\mathrm{kx}\left(1+\mathrm{k}+\mathrm{k}^{2}+\mathrm{k}^{3}+\ldots\right)$ $=\mathrm{k} /(1-\mathrm{k})$, if the source neutron is assumed to have the same multiplication constant as the subsequent fission neutrons. The total number of neutrons potentially available for transmutation is $[1+\mathrm{k} /(1-\mathrm{k})]$.

The fusion device uses a similar blanket but modified by a lithium component that absorbs one blanket neutron per source neutron. For the same blanket coverage, the total number of available neutrons is $\mathrm{k} /(1-\mathrm{k})$, which is $\mathrm{k}$ times as many as in the ATW blanket. 
One can also derive an equivalent multiplication constant k' of the fusion blanket from the relation

$$
\mathrm{k}^{\prime} /\left(1-\mathrm{k}^{\prime}\right)=\mathrm{k} /(1-\mathrm{k})-1, \quad \text { or } \mathrm{k}^{\prime}=2-1 / \mathrm{k} .
$$

Then the total number of available neutrons in the fusion device blanket is $[1+$ $\left.\mathrm{k}^{\prime} /\left(1-\mathrm{k}^{\prime}\right)\right]$, where $\mathrm{k}^{\prime}<0$ when $\mathrm{k}<0.5$. This formulation is used in the following to calculate blanket energy multiplication.

Since each fission reaction produces 3.0 neutrons, the fission energy per source neutron produced in the blanket is approximately $180 \mathrm{MeV} x \mathrm{k} /(1-\mathrm{k}) / 3=60 \mathrm{MeV} x$ $\mathrm{k} /(1-\mathrm{k})$. This relation is strictly valid only when the actual neutron multiplication is considerably greater than 3 , corresponding to $\mathrm{k} \geq 0.8$.

The total blanket energy per source neutron in the ATW is approximately

$$
25+60 \mathrm{k} /(1-\mathrm{k}) \mathrm{MeV} \text {. }
$$

The total blanket energy per source neutron in the fusion device is approximately

$$
19+60 \mathrm{k}^{\prime} /\left(1-\mathrm{k}^{\prime}\right) \mathrm{MeV}=-41+60 \mathrm{k} /(1-\mathrm{k}) \mathrm{MeV}
$$

where $19 \mathrm{MeV}$ is the sum of the energies of the source neutron and the Li6 capture reaction.

\section{CASE WITH NO BLANKET ENERGY CONVERSION}

The electricity consumed per available neutron in the ATW at $100 \%$ blanket coverage is

$$
25 \mathrm{MeV} /[\eta \mathrm{b}(1+\mathrm{k} /(1-\mathrm{k}))]
$$


The electricity consumed per available neutron in the fusion device at $100 \%$ blanket coverage is

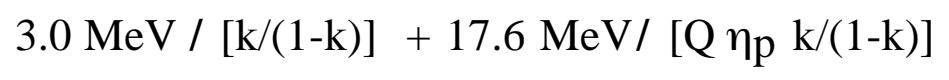

where the $3.0 \mathrm{MeV}$ is derived by apportioning the $50 \mathrm{MWe}$ non-plasma energy consumption over an assumed fusion neutron production of $1.0 \times 10^{20} \mathrm{n} / \mathrm{s}$, corresponding to fusion power of $285 \mathrm{MW}$. The first term is very small compared with the second unless $\mathrm{Q} \gg>1$, and therefore the result is relatively insensitive to the assumed fusion power.

Dividing Eq. (5) by Eq. (4), the ratio Rin of electrical energy consumed per available neutron in the fusion plant to that in the ATW is

$$
\mathrm{R}_{\mathrm{in}}=0.12 \eta_{\mathrm{b}} / \mathrm{k}+0.70 \eta_{\mathrm{b}} /\left(\mathrm{Q} \eta_{\mathrm{p}} \mathrm{k}\right)=(0.05+0.79 / \mathrm{Q}) / \mathrm{k}
$$

Figure 1 shows $\mathrm{R}$ in versus $\mathrm{Q}$ for several k-values. This ratio decreases as $\mathrm{Q}$ increases, since less power is needed to maintain the fusion plasma at constant neutron output. $\mathrm{R}_{\mathrm{in}}$ also decreases as $\mathrm{k}$ increases, since a smaller fraction of the blanket neutrons are needed to breed tritium. For $\mathrm{k} \ll<1$, corresponding to little neutron multiplication, $\mathrm{R}_{\mathrm{in}} \gg 1$ because there are few available neutrons in the fusion device blanket. For typical $\mathrm{k}=0.8-0.9$, corresponding to neutron multiplication of 5 to $10, \mathrm{R}_{\mathrm{in}} \approx 0.9 / \mathrm{Q}$. The electrical requirements are comparable at fusion energy "breakeven" $(\mathrm{Q}=1)$, and shift rapidly in favor of the fusion device as $\mathrm{Q}$ increases. At $\mathrm{Q}=10$, the fusion device consumes about $1 / 7$ as much power as the ATW per available neutron. 


\section{WITH CONVERSION OF BLANKET ENERGY TO ELECTRICITY}

Now we assume that the blanket thermal energy is converted to electricity with an efficiency $\eta_{\mathrm{e}}=0.37$, and calculate the minimum $\mathrm{k}$ that will provide overall electrical energy balance.

In the ATW case, energy balance per source neutron using Eq. (2) with $100 \%$ blanket coverage gives

$$
\eta_{\mathrm{e}}[25+60 \mathrm{k} /(1-\mathrm{k})]=25 / \eta_{\mathrm{b}} \text {, from which } \mathrm{k}=0.68 \text {. }
$$

A k-value of 0.68 corresponds to about two-thirds of a fission reaction (producing 120 $\mathrm{MeV}$ ) for each source neutron.

In the fusion case, energy balance per source neutron using Eq. (3) with $100 \%$ blanket coverage gives

$$
\eta_{\mathrm{e}}\left[19+60 \mathrm{k}^{\prime} /\left(1-\mathrm{k}^{\prime}\right)\right]=3.0+17.6 / \mathrm{Q} \eta_{\mathrm{p}}
$$

When $\mathrm{Q}=1$, Eq. (7) gives $\mathrm{k}^{\prime}=0.64$, corresponding to $\mathrm{k}=0.74$. These values of $\mathrm{k}$ are actually smaller than required for the validity of Eqs. (2) and (3). Nevertheless, the similarity of the blanket performance requirements when $\mathrm{Q}=1$ is consistent with the conclusion of the previous section.

The destruction of transuranic nuclides requires fission, so that it is likely that $\mathrm{k}$ will exceed 0.8 and either plant would produce considerable electrical power for sale in excess of the recirculating power. From Eqs. (2) to (5), we can derive $R_{n e t}$, the ratio of net electrical energy for sale, per available neutron: 


$$
\mathrm{R}_{\text {net }}=\frac{\text { net elect. prod. fusion plant }}{\text { net elect. prod. ATW }} \approx \mathrm{k} \frac{\mathrm{k} /(1-\mathrm{k})-0.82-2 / \mathrm{Q}}{\mathrm{k} /(1-\mathrm{k})-2.1}
$$

Figure 2 shows $\mathrm{R}_{\text {net }}$ versus $\mathrm{Q}$ for several $\mathrm{k}$-values. At typical $\mathrm{k}=0.8, \mathrm{R}_{\mathrm{net}} \approx 0.5$ when $\mathrm{Q}=1$ and 1.06 when $\mathrm{Q}=3$, increasing very slowly at higher $\mathrm{Q}$. As $\mathrm{k}$ approaches 1.0, $\mathrm{R}_{\text {net }}$ becomes 1.0 for all $\mathrm{Q}$, because at high neutron multiplication either plant looks much like a fission reactor, with minor recirculating power and a very small fraction of the neutrons diverted for tritium breeding.

\section{CAPITAL COST COMPARISON}

The ATW concepts typically use a $100-\mathrm{mA} 1-\mathrm{GeV}$ accelerator beam that produces $2.4 \times 10^{19}$ spallation neutron/sec. The estimated cost of the total plant including power conversion is about $\$ 3.0 \mathrm{~B}(\underline{1}, \underline{2})$.

The fusion source produces $3.5 \times 10^{17} \mathrm{P}_{\text {fus }} \mathrm{D}-\mathrm{T}$ neutron/sec, where $\mathrm{P}_{\text {fus }}$ is the fusion power in megawatts. As shown in Sec. II, the fusion blanket has k times as many available neutrons per source neutron as the ATW blanket, for the same blanket coverage.

Hence the capital cost per available neutron in the blanket is the same for the fusion and ATW plants if the fusion plant costs

$$
\$ 3.0 \mathrm{~B} \cdot \mathrm{k}\left(3.5 \times 10^{17} \mathrm{P}_{\text {fus }} / 2.4 \times 10^{19}\right) \mathrm{R}_{\mathrm{B}}=\$ 4.4 \mathrm{~B} \cdot\left(\mathrm{P}_{\text {fus }} / 100\right) \mathrm{k} \mathrm{R}_{\mathrm{B}},
$$

where $R_{B}$ is the ratio of blanket coverage of the fusion neutron source to that of the ATW, referring only to the waste modules. For example, if $\mathrm{P}_{\text {fus }}=300 \mathrm{MW}, \mathrm{R}_{\mathrm{B}}=2 / 3$ 
and $\mathrm{k}=0.8$, the fusion plant can cost up to $\$ 7$ billion and be competitive with the ATW.

\section{CONCLUSIONS}

The fusion plant has the same electrical power requirement per available blanket neutron as the ATW when the blanket coverage is comparable and fusion Q $\approx 1$, but the fusion plant has only a fraction of the power requirement when $\mathrm{Q} \gg 1$. This improvement offered by high Q could be a decisive advantage for the fusion device when the plant design or operating mode makes it impractical to convert blanket thermal energy or when the additional capital cost is daunting. In cases where the blanket thermal energy is converted to electricity, the fusion plant and ATW have comparable net electrical power outputs per available neutron when $Q \geq$ 2 , if the blanket coverages are the same.

For cost-competitiveness with an ATW costing \$3 B, the approximate capital cost of a 300-MW fusion plant with only $2 / 3$ of the blanket coverage of the ATW can be as large as $\$ 7 \mathrm{~B}$. 


\section{ACKNOWLEDGMENT}

This work was supported by the U.S. Dept. of Energy under Contract No. DEAC02-76-CHO-3073.

\section{REFERENCES}

1. "Nuclear Wastes -Technologies for Separations and Transmutation," National Academy Press, Washington, DC 1996.

2. “A Roadmap for Developing Accelerator Transmutation of Waste (ATW) Technology," U.S. Dept. of Energy Report DOE/RW-0519 (Oct. 1999).

3. E.T. Cheng and R.J. Cerbone, "Prospect of Nuclear Waste Transmutation and Power Production in Fusion Reactors," Fusion Technology 30 (1996) 1655. 


\section{Ratio of Electrical Energy Consumption}

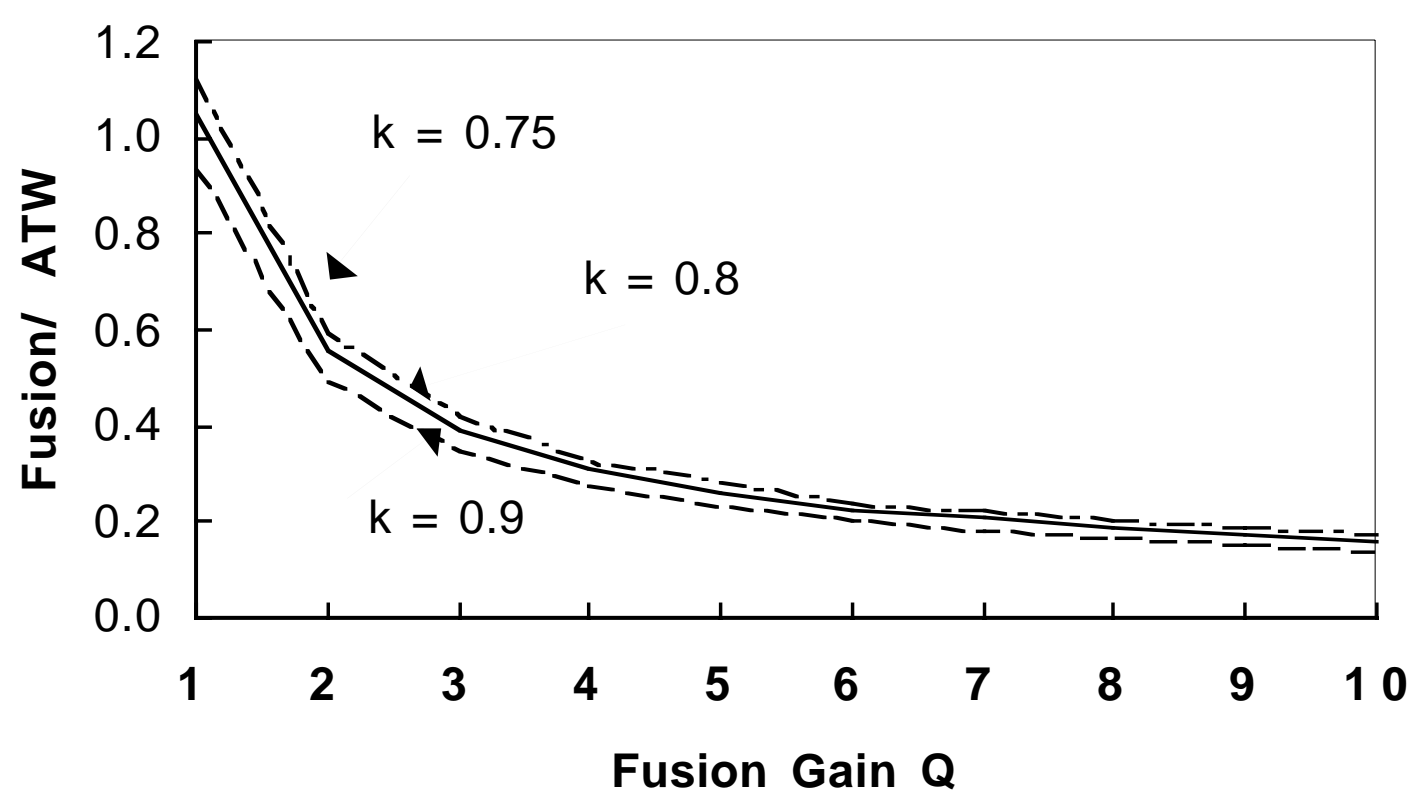

Fig. 1. Ratio of electrical energy consumed by the fusion device to that consumed by the ATW accelerator, per available neutron in the blanket. $\mathrm{k}$ is the neutron multiplication constant. 


\section{Ratio of Net Electrical Energy Production}

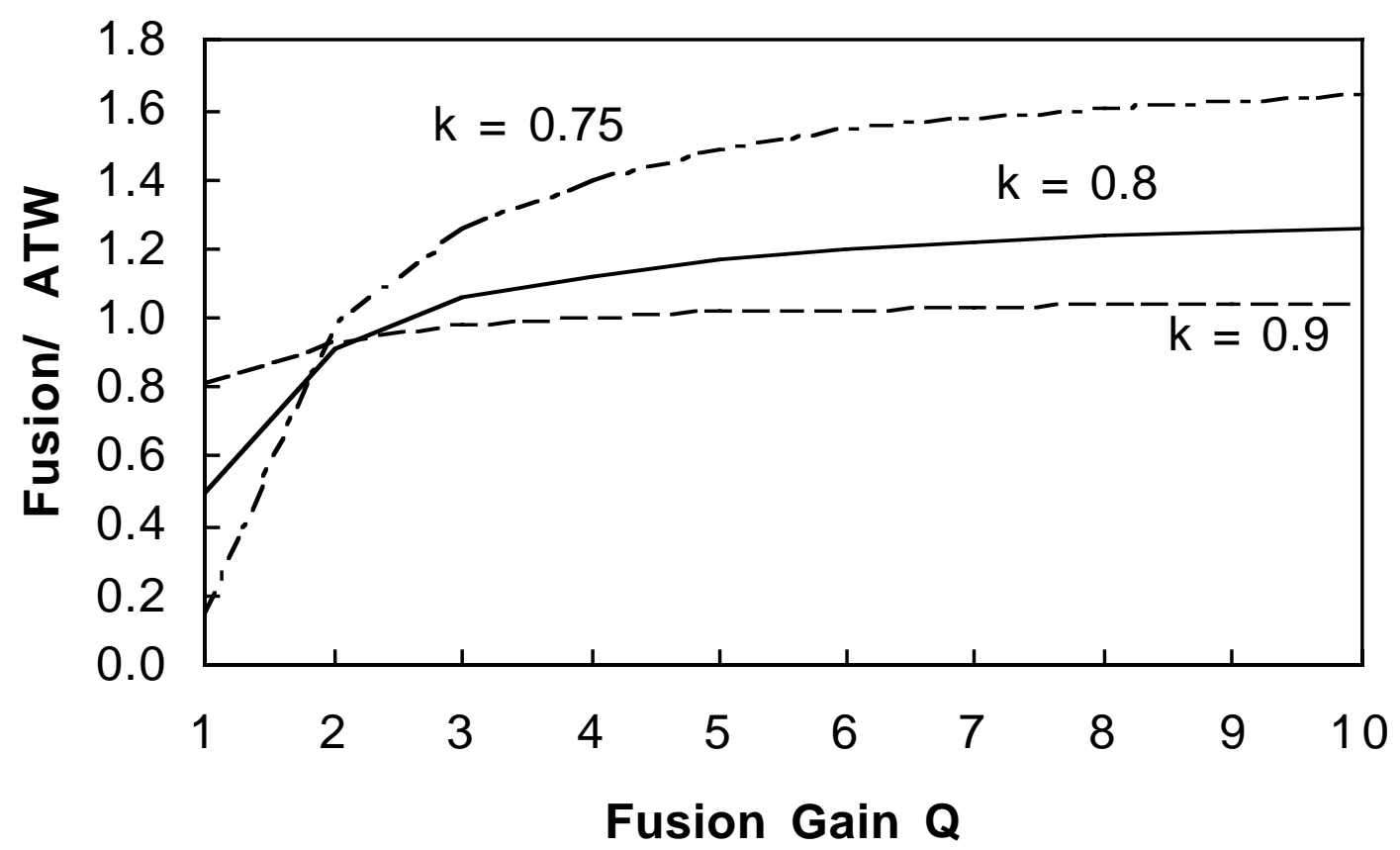

Fig. 2. Ratio of net electrical energy produced by the fusion device to that produced by the ATW plant, per available neutron in the blanket. $\mathrm{k}$ is the neutron multiplication constant. 